\title{
Breakdowns in Mediated Conversations: How and Why Youth Exit Cross-cutting Political Talk on Social Media
}

\author{
Ashley Lee \\ Stanford University \\ ashley.lee@stanford.edu
}

\begin{abstract}
Social media platforms are arguably reshaping how youth participate in politics today, but little is known about how youth navigate cross-cutting talk with different-minded others online. Based on in-depth interviews, this study examines the discursive strategies civic-minded youth employ to talk politics across lines of political difference on social media. Applying Hirschman (1970) to informal political talk, this study surfaces young people's "voice" and "exit" strategies in cross-cutting political talk [1]. Findings suggest that civic youth are well-versed in elements of rational deliberative discourse [2]. However, youth appear to struggle when it comes to relational discourse that emphasizes reciprocity and relational listening [3]. Youth tended to exit from political talk with different-minded others on social media. The low barriers for exit from cross-cutting talk on social media, combined with various psychosocial, dispositional factors, raise concerns about young people's premature exits from democratic engagement on social media.
\end{abstract}

\section{Introduction}

The recent US election cycles and the Brexit referendum have left people grappling with difficult questions about the state of political talk on social media. The widespread circulation and consumption of misinformation and disinformation have heightened concerns about the mass political polarization dividing the public along ideological and structural lines [4]. While the Internet initially seemed to harbor the potential to foster democratic dialogue and engagement across lines of political difference [5-7], increasingly there are concerns that the mechanisms and usage patterns of social media are fueling and accelerating the trend towards polarization and social fragmentation [8-10].

This study examines how civic-minded youth are engaging in political talk across lines of ideological difference on social media. Deliberative theories of democracy have pointed to the persistence of disagreements in democratic life and the centrality of free and open discussions to democratic practice [2, 11]. An emerging body of literature shows how youth are creatively leveraging social media to engage in political expression on social media [12-15]. Yet, less is known about how youth engage in "cross-cutting" political talk across lines of ideological difference on social media, where diverse voices vie for attention and influence.

\subsection{Youth and cross-cutting political talk on social media}

By "political talk," I refer to informal back-andforth exchanges with others about issues of public concern, rather than structured discussions or goaloriented deliberation [12]. Political talk is regarded as an important form of young people's political participation in and of itself [16]. Through political talk, young people may learn to process information about public affairs, form their own opinions, and gain exposure to alternative viewpoints.

Studies have shown that cross-cutting political talk - or political talk across lines of ideological difference-is difficult to achieve. Previous research in the offline context suggests that as heterogenous voices join the political mix, individuals tend to withdraw from political talk while others double down on their stances [17-20]. Evidence is mixed on whether cross-cutting exposure leads to increased or decreased political participation [18].

The dynamics and practices of political talk on social media depart in important ways from those of face-to-face political talk. Social media platforms bring together close and distant others, friends and strangers in 'context collapse,' creating infinite sets of imagined audiences [21]. Managing interactions in 'networked publics' is further complicated by persistence, replicability, scalability, and searchability of online expression [22]. 
Norms, content, and design affordances of specific platforms are also known to encourage or constrain youth political expression [13, 15, 23]. For instance, anonymity may mitigate some of the challenges of political talk on social media [15, 23]. Popular culture content on social media may encourage collective political expression by allowing young people to frame political issues in language that speaks to them [13, 23]. Memes, images, and videos form important parts of youth political expression [13, 23].

The digital context poses unique challenges of communicating with and responding to disembodied voices in an environment that is characterized by the lack of shared norms. Many youth are reluctant to express political opinions on Facebook due to uncertainty and ambiguity arising from 'social groundlessness' [24]. Individual orientation toward conflict is also an important predictor of young people's posting behaviors on Facebook [14]. In the presence of disagreement on Facebook, conflict avoidant individuals tend to shy away from using the platform for political discussion, while conflictseeking individuals ('provocateurs') tend to post more frequently [14]. Studies have also noted how some people frame their political posts in terms of neutral information sharing and humor in order to avoid 'drama' and controversy on social media [14, $24,25]$.

\subsection{Relational ethics in cross-cutting talk}

Drawing on Hirschman's Exit, Voice, and Loyalty [1], this study develops a framework for analyzing young people's engagement and disengagement strategies in cross-cutting talk. Hirschman suggests that customers respond to declining products in two ways: 1) withdraw their demand ("exit"); or 2) stay with the company out of loyalty and demand improvement ("voice"). Similarly, encountering opposing views online, youth may choose "exit" or "voice" as strategic responses.

On social media, people may employ "exit" strategies to disengage themselves from content, relationships, affiliation, network, and platforms [2628]. Politically motivated unfriending is a popular strategy to manage relationships. It personalizes the ideological boundaries of networked public spheres [26]. In practices of 'media refusal,' users abstain from using corporate social media platforms [27]. Here, corporate media platforms themselves become targets and sites of consumer resistance. Not surprisingly, people have different understandings of what it means to refuse - or exit - certain platforms, and they enact their 'exit' in different ways [27].
Relatedly, studies on romantic relationships have shown that social media create new social norms and media practices around ending relationships, as well as signaling and managing breakups [28].

An alternative to exit is to voice. Young people may voice and engage in argumentation in crosscutting political talk. Existing studies on argumentative strategies in the pre-digital context offer rich insights on the pragmatic dimensions of rational, argumentative discourse. While these studies tend to focus on resolving differences in opinion [29], we may posit a more relational model of discourse. In contrast to Habermas's emphasis on rational deliberative discourse, Bakhtin and Levinas locate dialogic ethics in "an open and ongoing obligation to respond to the other, rather than a static march toward some philosophical end or conclusion" $[3,30$, 31]. This relational model of discourse goes beyond rational reasoning and argumentation to emphasize relationship building and reciprocity with the different-minded other. Youth may engage in this kind of "ethical listening" and relationship building with different-minded others. Though little is known about why youth may persist in cross-cutting political talk, we may posit that youth choose to engage out of a sense of "loyalty" - or a sense of responsibility - to the different-minded other, the secondary audience, the larger society, etc. Here again, the digital context introduces additional layers of challenge to "ethical listening." Levinas' dialogic ethics is predicated on one's ethical responsibility to the other face-to-face.

\subsection{Psychosocial barriers to cross-cutting talk}

A key concern about cross-cutting talk on social media is that individuals - intentionally or unintentionally_may coalesce into self-reinforcing groups, affirming each other's beliefs and blocking out information that could challenge their views [32, 33]. While evidence is inconclusive, there are concerns that online polarization may be fueled by the filter bubble, which exposes users only to content that aligns with their past online preferences [10]. Uncomfortable or less familiar ideas get filtered out, and purviews become narrower.

Psychologists suggest that individuals tend to steer clear of contradictory views or data that conflict with their views (cognitive dissonance) [34]; or think what is familiar is truth (cognitive ease) [35]; or focus on data that reinforce their existing beliefs (confirmation bias); or double down on their beliefs after seeing data that contradict their beliefs (backfire effect) [36]. Such psychosocial mechanisms may pose formidable barriers to young people who engage in cross-cutting political talk on social media. 
Existing studies of online political talk and behavior based on large-scale surveys and big data analysis offer limited insights into the meaningmaking process of individuals - that is, how and why individuals deploy certain discursive strategies in cross-cutting talk [25]. The current study seeks to expand our understanding of discursive moves civicminded youth employ in cross-cutting talk on social media, along with considerations and predispositions that inform their choices in terms of strategies.

\section{Research questions}

This article explores three inter-related questions:

- RQ1: What discursive moves do youth employ in cross-cutting political talk on social media?

- $R Q 2$ : What considerations inform their strategic choices to exit cross-cutting political talk on social media?

- RQ3: What are some dispositional barriers that may inhibit youth from engaging in cross-cutting political talk on social media?

\section{Methods}

This article draws on in-depth interviews with 38 U.S.-based, civic-minded youth, who use social media extensively to engage with issues of public concern. Over a nine-month period in 2015 , a team of four researchers including the author administered surveys and conducted in-depth interviews, either in person or via an online videoconferencing platform. The study used purposive sampling, targeting a diverse group of youth along the lines of age, gender, race and ethnicity. The study targeted youth who post frequently about issues of public concern on social media (daily or weekly), and have used social media to engage with public issues for at least two years. Participants were identified through student organizations, community and youth organizations, youth workers and educators, and media coverage of young people's online civic action. The research team aimed to recruit youth who represented a variety of issues and viewpoints, ranging from racism to climate change, women's rights, LGBTQ+ issues, health care reform, refugee issues, immigration reform, and economic inequality.

The interview subjects ranged in age from 15 to 25 (mean $=20$ ). Of our participants, 22 were female and 16 were male. 17 identified as White; 10 as African American; 2 as Hispanic; 6 as Asian; 3 as multi-ethnic. All participant names have been changed to pseudonyms chosen by the participant at the time of the interview to protect their identities.
Prior to each interview, participants completed a pre-interview survey. The survey confirmed their eligibility and collected initial data about their media use, civic activities, and educational supports related to digital media literacy and civic engagement. Each interview lasted 90-120 minutes. The interviews focused on meaning-making and experiences with online civic participation; strategies (or alternatively, "moves") they used to participate in conversations; and motivations and considerations for their strategic choices. The interviews were accompanied by a walkthrough of the participant's social media profile and news feed. Interviews were digitally recorded and transcribed verbatim.

Using a combination of thematic and discourse analysis, a team of four researchers developed a coding scheme comprised of emic and etic codes. The research team obtained reliability ( $\kappa$-statistic of 0.7 or higher) by coding select transcripts, comparing codes, resolving disagreements, and refining code definitions. Subsequently, four members of the team divided up and coded the remaining transcripts independently. Each transcript was shadow coded by another coder to maintain reliability.

This paper reports results from coding and analysis focused on discursive moves (or alternatively, strategies) youth employed in conversations, and considerations that inform their strategic choices. Moves refer to higher order goals or strategies, such as "questioning," "storytelling," and "mobilizing." Moves may be verbal, multimodal, or non-verbal. Tactics refer to more specific mechanisms through which moves are enacted, such as "hyperlinking" and "hashtagging." For example, as part of the "mobilizing" move, a participant may use provocative images, and adjust tone to appeal to a target audience.

Applying Hirschman's framework to the political context [1], this study considers voice and exit moves in online cross-cutting talk. I identified three common types of moves that youth employed to engage with, or disengage from, cross-cutting talk (see Table 1) [1]. The first category is the argumentative or persuasive moves civic youth deployed to take and communicate a stance, persuade others, and stand their ground online. The emphasis here is on presenting arguments, evidence, and counter-arguments. The second category comprises listening moves used to genuinely listen to and engage differences in a conversation. Participants employ listening moves to enact ethical listening and to delve into the different other's beliefs and assumptions, and in doing so, learn about their own beliefs and assumptions. For instance, using listening moves, participants may check her own interpretation 
of the other person's words, or indicate where she agrees with the other person. Argumentative moves in their ideal execution embody Habermasian discourse ethics of rationality, whereas the listening moves emphasize the relational ethics of listening to the other [3, 30]. Finally, the exit moves are used to pull back from online interactions. The first two categories of moves ("voice" moves in Table 1) involve an exercise of voice, while the last category is marked by a withdrawal of voice ("exit" moves in Table 1) [1].

Table 1. Three types of moves

\begin{tabular}{|c|c|l|}
\hline \multicolumn{2}{|l|}{ Classification } & Category Description \\
\hline 1. Voice moves & Exercise of voice \\
\hline a. & $\begin{array}{l}\text { Argumentative / } \\
\text { persuasive moves } \\
\text { Listening moves }\end{array}$ & $\begin{array}{l}\text { Strategic moves made to argue with } \\
\text { or persuade the other(s) }\end{array}$ \\
\hline 2. Exit moves & $\begin{array}{l}\text { Strategic moves made to listen to and } \\
\text { learn about differences }\end{array}$ \\
\hline & Withdrawal of voice \\
\hline & $\begin{array}{l}\text { Strategic moves made to disengage } \\
\text { from the online encounter }\end{array}$ \\
\hline
\end{tabular}

\section{Findings}

\subsection{Exiting disagreement on social media}

Youth deploy an extensive repertoire of persuasive moves and tactics to line up, present, and reinforce their arguments and counter-arguments often using a complex combination and sequence and paying careful attention to platform affordances and target audience characteristics. Persuasive moves and tactics range from something as simple as backing up one's opinions with facts; stating the participant's opinion in a neutral or humorous tone- to more complex moves such as creating compelling internet memes; forming strategic alliances with celebrities online to circulate advocacy content; and creating social media campaign bundles for easy deployment by partners (see Table 2). For example, Josh, a 22year-old who is active on social justice issues, carefully hyperlinks news articles not only to back up his point, but also to grab the reader's attention with an eye-catching image accompanying the articles: In some cases, youth have accumulated "packages" of tried-and-true moves and tactics over time. As Scooby (age 21) who is engaged in Israel-Palestine issues shares:

What happens more is, I get accustomed to different lines of argumentation, and I learn better at how to respond and what facts to draw from and what's effective, and what people respond better to.

However, when youth encounter disagreement, they turn to a reduced set of moves and tactics, leaving behind their eloquent arguments. In cross-cutting talk, the repertoire of argumentative moves is more or less reduced to stating their points-of-view, "provoking" and "informing" the other person (see Table 2).

\section{Table 2. Examples of argumentative / persuasive moves}

\begin{tabular}{|l|l|l|}
\hline Move & $\begin{array}{l}\text { No. of youth } \\
\text { who reported } \\
\text { using this } \\
\text { move in online } \\
\text { political talk }\end{array}$ & $\begin{array}{l}\text { No. of youth } \\
\text { who reported } \\
\text { using this } \\
\text { move when } \\
\text { they encounter } \\
\text { disagreements }\end{array}$ \\
\hline $\begin{array}{l}\text { Challenging, provoking } \\
\text { Example. Posting a Facebook } \\
\text { status update with provocative } \\
\text { content to start a discussion on } \\
\text { an issue }\end{array}$ & $25(66 \%)$ & $8(21 \%)$ \\
\hline $\begin{array}{l}\text { Storytelling } \\
\text { Example. Posting a personal } \\
\text { story related to an issue }\end{array}$ & $17(45 \%)$ & $0(0 \%)$ \\
\hline $\begin{array}{l}\text { Educating, Informing } \\
\text { Example. Tweeting links to news } \\
\text { articles with the subject's own } \\
\text { commentary; posting links to } \\
\text { online resources }\end{array}$ & $38(100 \%)$ & $7(18 \%)$ \\
\hline
\end{tabular}

At the same time, exit moves become most prevalent among civic youth in cross-cutting talk (see Figure 1). Nearly all youth in the sample report using exit moves in cross-cutting talk. Exit moves unfold along both temporal and spatial axes - youth may cut down the audience and network, or avoid getting into disagreements in the first place. Exit moves include "unfriending", "unfollowing", withdrawing from a conversation thread, ignoring, cutting back the audience, deleting content, and avoiding different others in the first place (see Table 3). These moves are not passive absence of voice, but strategic choices made by the individual. Sarah, for example, a high school student (age 17) who has launched a women's empowerment campaign online, describes herself as non-confrontational and shares how she stays clear of controversial issues:

I think that I personally try to avoid really, really touchy subjects. So, if it is... for pro-choice or abortion, something really, really touchy that I know I've seen people arguing over on my social media feed...

Charlotte (age 21) makes a point of surrounding herself with people who share her views on women's rights and health issues, which are very important to her.

So yeah, I have a lot of friends that share the same views. I really make a point to... I really don't get along with people... Like, these things are so important to me that I really don't get 
along with people that don't share them, so I make it a point to not have them in my life [chuckles].

Charlotte has scaled back her audience to those who share her views on women's rights and health issues. Like Charlotte, some civic youth exhibit intolerance of those who do not share similar views on issues of importance to them.

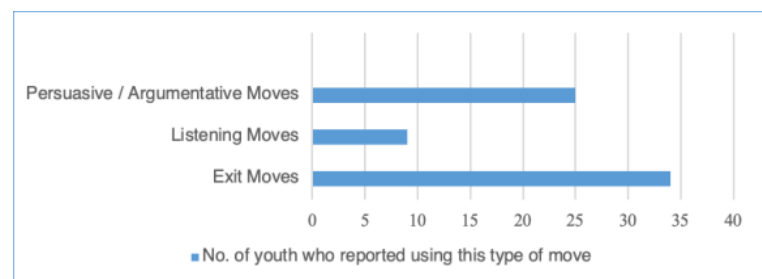

Figure 1. Move usage in cross-cutting talk

Table 3. Examples of exit moves

\begin{tabular}{|l|l|l|}
\hline Move & $\begin{array}{l}\text { No. of youth } \\
\text { who reported } \\
\text { using this } \\
\text { move in online } \\
\text { political talk }\end{array}$ & $\begin{array}{l}\text { No. of youth } \\
\text { who reported } \\
\text { using this } \\
\text { move when } \\
\text { they encounter } \\
\text { disagreements }\end{array}$ \\
\hline Unfriending, unfollowing & $13(34 \%)$ & $7(18 \%)$ \\
\hline Blocking & $12(32 \%)$ & $5(13 \%)$ \\
\hline $\begin{array}{l}\text { Not responding to particular } \\
\text { comment/thread }\end{array}$ & $24(63 \%)$ & $21(55 \%)$ \\
\hline $\begin{array}{l}\text { Exiting, withdrawing, no longer } \\
\text { engaging in a thread }\end{array}$ & $11(29 \%)$ & $7(18 \%)$ \\
\hline Limiting one's audience & $21(55 \%)$ & $1(3 \%)$ \\
\hline Reporting to site administrator & $4(1 \%)$ & $2(5 \%)$ \\
\hline Deleting a post & $12(32 \%)$ & $8(21 \%)$ \\
\hline
\end{tabular}

In disagreement, an alternative to voicing one's stance or exiting the conversation is to stay in the conversation and listen. A small group of participants use what I call listening moves to engage in performative listening. These youth employ listening moves to engage, probe, and explore perspectives of different-minded others online. Listening moves include acknowledging what the other person has said; connecting ideas; reflecting back on what the other person has said; and engaging in appreciative inquiry (see Table 4).

Sassy is one of those few who employ listening moves to try to work it out with a different-minded other. Sassy, age 22, is active in issues of racism, sexism, and youth voice. Sassy shares how she and her friend were on two different sides, but they stuck to it to work it out.

Well, she was willing to participate because some people don't want to keep it going. I was willing to participate. So, she was saying some interesting things. I don't remember exactly what she said but I could see that she had thought about this or was thinking about it, and I wanted to wrestle those thoughts with her. I know that I challenged her on a personal level to just... We were both challenging each other, right? She challenged me in a certain way too to think about the problem in a different context...

Even though Sassy does not agree with the other person's viewpoint, she employs listening moves to "wrestle those thoughts" and dig deeper into both her own and the other person's perspectives. She keeps responding, questioning, and challenging the other person, opening up possibilities of a new understanding of the problem in a different context and moving each other to different points of disagreement. Youth like Sassy who adopt listening moves to explore differences in disagreements are impressive but rare. Altogether, these findings suggest that among this group of youth, open-minded dialogue based on ethical, reciprocal listening practices is rarely achieved on social media.

\section{Table 4. Examples of listening moves}

\begin{tabular}{|l|l|l|}
\hline Move & $\begin{array}{l}\text { No. of youth } \\
\text { who reported } \\
\text { using this } \\
\text { move in online } \\
\text { political talk }\end{array}$ & $\begin{array}{l}\text { No. of youth } \\
\text { who reported } \\
\text { using this } \\
\text { move when } \\
\text { they encounter } \\
\text { disagreements }\end{array}$ \\
\hline $\begin{array}{l}\text { Appreciating, Respecting } \\
\text { Example. Expressing } \\
\text { appreciation for different } \\
\text { perspectives }\end{array}$ & $13(34 \%)$ & $1(3 \%)$ \\
\hline $\begin{array}{l}\text { Connecting } \\
\text { Example. Trying to find a } \\
\text { common ground between the two } \\
\text { parties in a disagreement }\end{array}$ & $25(66 \%)$ & $3(8 \%)$ \\
\hline $\begin{array}{l}\text { Acknowledging } \\
\text { Example. Acknowledging the } \\
\text { other person for sharing a } \\
\text { different perspective in a } \\
\text { comment thread }\end{array}$ & $9(24 \%)$ & $1(3 \%)$ \\
\hline $\begin{array}{l}\text { Reflecting back, Checking } \\
\text { interpretation }\end{array}$ & $4(11 \%)$ & \\
$\begin{array}{l}\text { Example. Summarizing the other } \\
\text { person's comments to check } \\
\text { one's own interpretation. }\end{array}$ & & \\
\hline
\end{tabular}

\subsection{Why youth exit cross-cutting talk}

In cross-cutting talk on social media, many youth $(n=25)$ vary between voice and exit moves. When and why do these youth choose exit moves over voice moves? Below, I delve into key considerations that inform young people's strategic choices to pull back from cross-cutting talk online. Table 5 summarizes five key dimensions of considerations that youth frequently brought up in the interviews.

Table 5. Key considerations informing youth
decision to exit cross-cutting political talk 


\begin{tabular}{|l|ll|}
\hline $\begin{array}{l}\text { (1) Issue-related } \\
\text { considerations }\end{array}$ & - & $\begin{array}{l}\text { Is this issue important to me? } \\
\text { Is this issue controversial? }\end{array}$ \\
\hline $\begin{array}{l}\text { (2) Audience-related } \\
\text { considerations }\end{array}$ & - & $\begin{array}{l}\text { Is the other person receptive to my } \\
\text { view? } \\
\text { Is the larger audience receptive to my } \\
\text { view? }\end{array}$ \\
\hline $\begin{array}{l}\text { (3) Impact-related } \\
\text { considerations }\end{array}$ & - & $\begin{array}{l}\text { Will I change anyone's mind? } \\
\text { Will having this conversation make a } \\
\text { difference? } \\
\text { Will the audience learn something from } \\
\text { this conversation? }\end{array}$ \\
\hline $\begin{array}{l}\text { (4) Considerations } \\
\text { related to issue } \\
\text { knowledge }\end{array}$ & - & $\begin{array}{l}\text { Do I know enough about this issue to } \\
\text { engage in this convesation } \\
\text { productively? }\end{array}$ \\
\hline $\begin{array}{l}\text { (5) Considerations } \\
\text { related to personal } \\
\text { risks }\end{array}$ & - & $\begin{array}{l}\text { Is there potential risk (e.g. backlash) } \\
\text { associated with engaging in this talk? }\end{array}$ \\
\hline
\end{tabular}

Many young people choose exit moves when discussions get heated or the conversation turns to controversial issues (issue-related consideration). Even though Lauren (age 19) is willing to engage across lines of political difference, she exits crosscutting conversations before they get heated: "So even if we disagree on something, I try to find a common ground. And I also choose to just ignore someone before it becomes a hot issue." Charlotte similarly heads for the exit when a conversation with her Republican uncle takes an unexpected turn. When her uncle posts an image that equates the Democrats who support Obamacare with the Democrats of the past who "didn't want to end slavery," Charlotte initially uses argumentative moves to challenge her uncle and state her point of view:

I was like, "Hey, there's a thing called party realignment that happened during the Progressive Era.” Like, “... It just doesn't make sense... Nothing in this graphic makes sense." ... [My uncle] was like, "I don't need your liberal inebriated Kool-Aid rants."

She has a back and forth with her uncle and his friends, but when her uncle's friends pile up against her and the audience turns uncivil (audience-related consideration), Charlotte heads for the exit and "unfriends" her uncle:

Then all of his 45-year old, middle age, conservative friends started attacking me, and like, “...I bet she loves Obama,” and just talking about things that had nothing to do with what I [had] said. And so I commented again, and I was like, “... It doesn't make sense. It's fine if you'll post political opinions, but don't share things like this because it's just... scare tactics..." And they just ignored me again, and just started personally attacking me again. So yeah, so I removed my uncle from my Facebook...

As a result of such negative encounters, Charlotte now refrains from commenting:
I used to get involved. If I saw an opinion I did not like, and I would get involved, I'll comment, but they would just ignore what I said or attack me personally. So I really... I kind of stayed away from that.

After negative encounters like this, some young people subsequently backed away from engaging opposing views on social media.

For many, seeking out and engaging opposing points-of-view is not necessarily high priority. Cole, a 21-year-old college student involved in environmental issues, prioritizes his efforts on people who are undecided or receptive to his views rather than engaging with people who hold opposing views (impact-related consideration). He pulls back from interactions that are not "worth it." In one instance, Cole starts a conversation with a climate change denier, but decides to move on quickly, given his time constraints and immediate goal of getting more people to sign his climate change petition. Cole, like many youth, is focused on mobilizing around his cause, and invests his time and resources in identifying supporters and persuading the undecided rather than engaging the opposite side.

In fact, many youth seem to gauge in advance how well their ideas would be received and skip situations where things could get too argumentative or come to a standstill. Many avoid being dragged through the mud by some "ignorant" other. For instance, young people like Cortana, a 17-year-old self-identified feminist, understand that social media offer opportunities to have a dialogue with others and to possibly change their minds, but they indicate that there needs to be some signs of receptivity to other points of views before they will start a conversation:

I would really like to be able to have a dialogue with him and try to help him see my point of view but at the same time... I think you have to be sort of at a baseline level of understanding in order for me to engage meaningfully, at least like within reasonable time constraints. So I think sometimes if people are too extreme on social media, that it discourages me from really starting a conversation with them.

Youth are more willing to defend their own positions, if someone disagrees with them on their own turf (i.e. disagreement on their posting or comment), but in general, many exhibit a "I just don't have time for that" kind of attitude towards disagreement online. Scooby, a seasoned debater, thinks that convincing others who disagree with him is not really a priority for him. Although Scooby does willingly engage when people post opposing comments on his own posts or when his friends ask him to step in to argue a 
side, most of the time, he scrolls past people thinking, "Okay. They're just posting something dumb again."

Youth like Kris altogether stay away from "back and forth" conversations with the opposite side. Kris, a 21-year-old college student who is active on campus sexual violence and LGBTQ issues, thinks that online interactions do not fundamentally change other people's minds and is skeptical that social media are effective for conversations across lines of difference (impact-related consideration): "I've never posted something and thought, 'Wow, a bunch of people now have totally had their minds changed because of a comment on a post." Kris further explains that he "unfriends" or "blocks" people who post "racist, sexist, homophobic" comments (audience-related consideration; consideration related to personal risks). Instead, he chooses to engage "different views" within a much more progressive circle:

I would say that [my audience] definitely skews towards a much more progressive group but within that progressive narrative, there are a lot of different views represented, sort of focuses that are represented.

Kris' perception of limited impact on social media platforms (i.e. a back-and-forth conversation on social media does not change people's minds), compounded by his concerns about uncivil audience on social media, leads him to exit from diverse circles online. Like Kris, many explore and engage "different" views within "safe" audiences composed of like-minded friends and circles online.

\subsection{Fight or flight: Predispositions that trigger premature exits from cross-cutting talk}

In addition to considerations that inform young people's decisions to employ exit moves, my analysis further shed light on predispositions that trigger premature exits from meaningful encounters with different others on social media. They are: predisposition to avoid conflict; predisposition to rely solely on gut instinct and emotion; and predisposition to approach dialogue as an "argument-war" or a zerosum game.

Many youth are conflict avoidant when it comes to political talk. Sam who describes himself as "nonconfrontational," sticks to non-controversial topics, and prefers to avoid negative topics. Kris, facing the challenges of uncivil language, usually opts for exit moves, a "non-response." Even the confident debaters, when faced with the challenges of uncivil language and potential backlash, turn to exit moves. As previous studies suggest [14], non-confrontational disposition interacts in complex ways with social and emotional factors and the individual's strategic considerations to produce exit behaviors.

Youth also talk about how they have an instinctive, emotional reaction to certain issues, information, opinions or attitudes of different-minded others. Intuition and emotions sometimes foreclose the possibilities of deeper engagement with both one's own and alternate views. Some young people mention that as they become more confident and knowledgeable about their issues, they rely on a more intuitive reaction to some ideas or even "recoil" from certain opinions that they consider to be undesirable or not aligned with their set beliefs. George, a 20year-old college student with interests in affirmative action and racial justice issues, shares,

$[\mathrm{M}] \mathrm{y}$ political stances don't change as much anymore, but it's because they're guided by the same view and the principles, I think. What those are? No idea. But it's kind of like one of those gut reactions to certain issues...

George leaves assumptions behind his strongly-held political beliefs mostly unexamined, but he hopes that they are based on values of equity and access.

When Kris reads, he tries to identify himself within the text or to empathize with certain elements, but he is quickly turned off by nuanced subtleties that are discriminatory or do not seem to fully grasp the issue at hand. Like George, Kris lets his "visceral reaction" guide him. Or as Rose more aptly characterizes it, "They were just wrong. They were just wrong and dumb."

Kris: I think part of that is sort of like that gut reaction that you get... Sort of like the biological learning of just like if you're having a visceral reaction to something, there's probably a good reason.

Here Kris engages in motivated reasoning based on his gut reaction.

Similar to the "gut" reaction, others bring up emotional reactions that they experience when encountering posts that are opposed to their own views. Some express a desire to avoid ideas that are contradictory to their own, or ideas that make them angry or uncomfortable. However, Michael (age 25) admits that even though he does not like it when people post ideas that he disagrees with, he understands that could be a starting point of a conversation: "I don't like when people post topics that I disagree with or points I disagree with. I think it's necessary 'cause then that's how we can start conversations." These examples illustrate how the predisposition to rely solely on "gut" reactions and affect becomes important drivers of "exit" moves. Youth talk about experiencing anxieties, 
uncertainties, and other negative emotions (e.g. anger, discomfort, embarrassment, awkwardness) in cross-cutting talk. Further, both anticipated and actual negative experiences, along with a lack of clear norms for social interactions online, appear to exacerbate conflict avoidance [24].

With strong negative emotion or intuitive beliefs, some youth default to reflex "exit" moves, as Kris and Megan do in the examples above [7, 34]. Others instantly default to a competitive mode in crosscutting interactions. Often, underlying such approach is the "us-versus-them" mental model in which dialogue is construed as an "argument-war" to be won or lost. Julian, a 15-year-old teen feminist and blogger, goes into a "shut-down-the-other-side" mode when she encounters the post of a "pro-life" supporter online. Reflecting back, Julian adds that she might have tried a different approach like attempting to "have a discussion rather than an argument."

The "us-versus-them" thinking does not always erupt in a "war" or "hissy-fits" as Megan describes, but can still undermine the dialogic relationship between interlocutors more subtly. George tries to learn about the opposite view in a conversation, yet for him, the conversation is primarily a means to strengthen his own argument vis à vis the other: Nothing helps the argument more than making sure that I know exactly what other side is saying... And I think for me it's always about seeking the opposite talking point to reinforce my own talking points.

Here, George engages with a different-minded other, but ultimately, his dialogue model is one of "using" the other to "reinforce" his own talking points. His dialogue does not build on the "dialogic ethics based on welcoming the other as partner rather than using or resenting him/her" [31]. George appears to engage in motivated reasoning [26] based on his prior beliefs, rather than engaging in constructive reasoning with the other side.

Similarly, for Scooby a skilled debater, a good discussion "destroys" the other side: "I think a good online discussion is where I just like destroy someone in debate." He adds, "I'm doing it not for the other person, [but] like for people to read and see these arguments critically engaged." Scooby approaches the dialogue as a kind of "political spectacle" he performs to educate the extended audience. In a sense, the conversation partner is co-opted as a means to an end rather than someone with whom one can co-create new meanings and perspectives through dialogue. Even as Scooby succeeds in skillfully turning a disagreement into a teachable moment, he may be losing sight of opportunities to arrive at a new understanding with his conversation partner. While boundary-making and identity work, "distinguishing 'us' from 'them,", is critical to building solidarity in activism and movements [38], the blanket "us-versus-them" approach to dialogue may preclude possibilities of transformative dialogue. Julian echoes this sentiment that many young people share: "I'm completely open to people arguing and discussing things with me, but I don't think I'll ever change my mind." Open discussions are good; arguments are important; but many young people express immunity on their part from being affected by them.

\section{Discussion}

Youth in this study actively tap into the affordances of social media to voice their opinions passionately and rally their causes. However, when they encounter different-minded others, they tend to exit from cross-cutting talk. These findings echo the arguments that in politics driven by passionate citizen participation, it may be challenging to create a deliberative public space $[18,33]$.

The youth in this study report willingness to be open-minded and to engage with diverse perspectives, but their online behaviors and predispositions often appear to reinforce and deepen echo chambers. Youth draw on extensive repertoires of argumentative moves to advance their civic goals and persuade others. However, in cross-cutting talk, exit moves become most prevalent. The study has also identified a small group of youth who use listening moves to enact ethical, reciprocal listening, especially in situations where differences arose. However, such youth are rare. Even though the civic youth seem well-versed in elements of rational deliberative discourse [2], they appear to struggle when it comes to forms of relational discourse that emphasize willingness and ability to listen and respond to different others [3]. Often, youth prematurely avoid or exit encounters with differentminded others, and the cross-cutting interactions, when they do take place, more closely resemble "a philosophical monologue unfolding dialectically" [3].

Not unlike the citizens in Eliasoph's study who take great care to avoid political talk offline [20], civic youth frequently exit from more difficult crosscutting conversations even as they raise their voices to advance their interests and causes. Like Kris, youth often report engaging with "different" perspectives within like-minded circles online. Even among youth who initiate or join conversations with different-minded others, a common pattern is to selectively withdraw from conversations that they see 
as "difficult," "controversial," or not "productive" in some way. This widespread selective engagement practice shows that youth limit when, how, and with whom they engage in cross-cutting conversations. The affordances of social media platforms [22] allow youth to tune in and out of conversations dynamically and selectively in a way that is harder to achieve in face-to-face settings.

This study thus surfaces what I call the selective engagement behavior. Selective engagement refers to strategic behaviors that individuals adopt to shift dynamically between voice and exit - in other words, tune in and out of conversations - so as to minimize what they perceive as undesirable consequences of cross-cutting political talk while maximizing what they see as potentially desirable outcomes (Figure 2). Selective engagement is thus related to - but distinct from-selective exposure, which refers to the human tendency to favor information which is more supportive of one's views over less supportive alternatives. For the most part, youth do not systematically cut off (e.g. 'unfriend', 'block') their network ties to different-minded others because of ideological differences [see also 37]. This picture aligns with previous findings which suggest that the presence of loose ties on social media can limit the possibility of selective exposure based on common interests and backgrounds [8]. At the same time, where cross-cutting talk does take place, the nature and quality of young people's discursive engagement with different-minded others remains thin. Even when youth are exposed (incidentally or otherwise) to cross-cutting views through their ties on social media, this study shows that they also adopt selective engagement practices to delimit when, how, and with whom they engage. These findings thus suggest that different kinds of echo chambers exist. The echo chambers created by selective exposure - the kind that has received much scholarly attention-likely have different boundaries and dynamics from the echo chambers created by selective engagement, which requires further examination.

As previous studies have noted, political talk on social media is embedded within the sociality of everyday life [20,24], and takes place in the context of existing social relationships, which are not necessarily driven by politics, though they can be. The blurring of the boundaries between the social and the political offers some explanation why youth do not always sever ties with individuals who have politically divergent views, and instead opt for the selective engagement approach.

Selective engagement is a practical approach. People cannot engage with every single disagreement that they encounter. However, there is some concern that youth practices of selective engagement may be becoming too selective, accelerating the trend toward a "pointillist public sphere" [33]. Incentives to engage in these difficult conversations are not immediately clear to many youth who are focused on near-term consequences or immediate impact of the conversation. The motivations and considerations youth share also raise questions about how openmindedly and accurately youth are interpreting the signs of the other's receptivity or assessing the potential impact and "productivity" of cross-cutting talk. Indeed, such interpretations and assessments may be further constrained by various dispositional barriers.

The overall picture depicts youth relying on reduced repertoires of speech and thought in crosscutting talk (e.g. reduced sets of dialogue and thinking strategies; shrinking circles of concern). For many youth, disagreement produces anxieties and negative emotions. The absence of social norms in online environments characterized by "social groundlessness" further adds to the compounding sense of uncertainty and negative emotions [24]. Such negative emotions can further narrow individuals' thought-action repertoires, constraining the use of open-minded dialogue strategies [35, 39]. The narrowing thought-action repertoires may lock individuals in ongoing cycles of "intuit-fight-flee" responses. The low barrier for exit on social media (e.g. a single click), combined with these multiple psychosocial factors, raises concerns about "the danger of premature and excessive exits" from crosscutting talk on social media [1]. Yet, as Papacharissi argues, citizens can and do "feel their way into" politics, and emotion and reason can inform-rather than work against - each other [7]. Intense feelings do not automatically preclude (nor precipitate) deep understanding or engagement with politics. Future research should investigate what makes some youth persist in cross-cutting talk, how they persist in spite of - or even because of - accompanying emotions, and how they develop effective moves over time.

The findings in this study cannot be generalized to a larger population. The sample leans toward college-educated, left-leaning youth. Future research should explore whether the patterns surfaced in this study hold among larger samples, and among individuals with different levels of digital and civic engagement and with different political leanings (e.g. right-learning youth). How young people's moves on social media compare to their moves in face-to-face conversations is another point of inquiry for future. More than ever, in today's polarized climate, it is critical to support young citizens to continue to build 
up and draw on their repertoires of discursive and thinking strategies for dialogue and listening.

Acknowledgements. This work was supported by the MacArthur Research Network on Youth and Participatory Politics. The author would like to thank Howard Gardner, Carrie James, Margaret Mullen, Daniel Gruner, and anonymous reviewers for their feedback.

\section{References}

[1] A. O. Hirschman, Exit, Voice, and Loyalty, Harvard University Press, Cambridge, MA, 1970.

[2] J. Habermas, The Structural Transformation of the Public Sphere, MIT Press, Cambridge, MA, 1991.

[3] M. M. Bakhtin, The Dialogic Imagination, University of Texas Press, Austin, TX, 1981.

[4] A. Marwick, and R. Lewis, "Media Manipulation and Disinformation Online", Data \& Society, New York, NY, 2017.

[5] J. Brundidge, "Encountering 'Difference' in the Contemporary Public Sphere", Journal of Communication, 60(4), 2010, pp. 680-700.

[6] L. Dahlberg, “The Internet, Deliberative Democracy, and Power", International Journal of Media \& Cultural Politics, 3(1), 2007, pp. 47-64.

[7] Z. Papacharissi, Affective Publics, Oxford University Press, Oxford, UK, 2015.

[8] E. Bakshy, S. Messing, and L. A. Adamic, "Exposure to Ideologically Diverse News and Opinion on Facebook", Science, 348 (6239), 2015, pp. 1130-1132.

[9] C. R. Sunstein, \#Republic, Princeton University Press, Princeton, NJ, 2017.

[10] E. Pariser, The Filter Bubble, The Penguin Press, New York, NY, 2011.

[11] A. Gutmann, and D.F. Thompson, Democracy and Disagreement, Harvard University Press, Cambridge, MA, 1996.

[12] M. Ekström, "Young People's Everyday Political Talk", Journal of Youth Studies, 19, 2016, pp. 1-19.

[13] I. Literat, and N. Kligler-Vilenchik, "Youth Collective Political Expression On Social Media”, New Media \& Society, 21(9), 2019, pp. 1988-2009.

[14] E.K. Vraga, K. Thorson, N. Kligler-Vilenchik, and E. Gee, "How Individual Sensitivities to Disagreement Shape Youth Political Expression on Facebook", Computers in Human Behavior, 45, 2015, pp. 281289.

[15] D. S. Lane, V. Das, and D. Hiaeshutter-Rice. "Civic Laboratories", Information, Communication \& Society, 22(14), 2019, pp. 2171-2186.

[16] A. Vromen, M.A. Xenos, and B. Loader, "Young People, Social Media, and Connective Action", Journal of Youth Studies, 18, 2015, pp. 80-100.

[17] D.C. Mutz, Hearing the Other Side, Cambridge University Press, Cambridge, UK, 2006.

[18] J. Matthes, J. Knoll, S. Valenzuela, D. N. Hopmann, and C. Von Sikorski, "A Meta-analysis of the Effects of Cross-cutting Exposure on Political Participation”, Political Communication, 36(4), 2019, pp. 523-542.

[19] L. Nir, "Disagreement and Opposition in Social
Networks", Political Studies, 59, 2011, pp. 674-692.

[20] N. Eliasoph, Avoiding Politics, Cambridge University Press, Cambridge, UK, 1998.

[21] A.E. Marwick, and d. boyd, "I Tweet Honestly, I Tweet Passionately: Twitter Users, Context Collapse, and the Imagined Audience." New Media \& Society, 13(1), 2011, pp. 114-133.

[22] d. boyd, "Social Network Sites as Networked Publics", In Networked Self, Identity, Community, and Culture on Social Networking Sites, Z. Papacharissi (Ed.), Routledge, New York, NY, 2010, pp. 39-58.

[23] I. Literat, and N. Kligler-Vilenchik. "How Popular Culture Prompts Youth Collective Political Expression and Cross-Cutting Political Talk on Social Media: A Cross-Platform Analysis.” Social Media+ Society, 7(2), 2021

[24] K. Thorson, "Facing an Uncertain Reception: Young Citizens and Political Interaction on Facebook", Information, Communication \& Society, 17(2), 2014, pp. 203-216.

[25] F. Giglietto, and Y. Lee, "A Hashtag Worth a Thousand Words: Discursive Strategies Around \#JeNeSuisPasCharlie After the 2014 Charlie Hebdo Shooting", Social Media + Society, 2017, pp. 1-15.

[26] N.A. John, and N. Gal. "'He's Got His Own Sea': Political Facebook Unfriending in the Personal Public Sphere." International Journal of Communication, 12, 2018, 2971-2988.

[27] L. Portwood-Stacer. "Media Refusal and Conspicuous Non-consumption”, New Media \& Society, 15(7), 2013, pp. 1041-1057.

[28] I. Gershon. "The Breakup 2.1: The Ten-year Update." The Information Society, 36(5), 2020, pp. 279-289.

[29] F. H. Van Eemeren, and R. Grootendorst. A Systematic Theory of Argumentation, Cambridge University Press. Cambridge, UK, 2004.

[30] M. Levinas, "The Paradox of Morality", In The Provocation of Levinas, R. Bernasconi and D. Wood (Eds.), Routledge, London, UK, 1988, pp. 168-80.

[31] J. Nealon, Alterity Politics, Duke University Press, Durham, NC, 1998.

[32] Y. Benkler, The Wealth of Networks, Yale University Press, New Haven, CT, 2006.

[33] E. Zuckerman, "New Media, New Civics?", Policy \& Internet, 6(2), 2014, pp. 151-168.

[34] L. Festinger, A Theory of Cognitive Dissonance, Stanford University Press, Stanford, CA, 1957.

[35] D. Kahneman, Thinking, Fast and Slow, Farrar, Straus and Giroux, New York, NY, 2011.

[36] B. Nyhan, and J. Reifler, "When Corrections Fail", Political Behavior, 32, 2010, pp. 303-330.

[37] R.K. Garrett, "Politically Motivated Reinforcement Seeking: Reframing the Selective Exposure Debate", Journal of Communication, 59(4), 2009, pp. 676-699.

[38] F. Polletta, and J.M. Jasper, "Collective Identity And Social Movements", Annual Review of Sociology, 27(1), 2001, pp. 283-305.

[39] N.H. Frijda, P. Kuipers, and E. Schure, "Relations among Emotion, Appraisal, and Emotional Action Readiness", Journal of Personality and Social Psychology, 57, 1989, pp. 212-228. 